\title{
Young consumers' motives for using SMS and perceptions towards SMS advertising
}

\author{
Ian Phau, Min Teah, Curtin University of Technology
}

\begin{abstract}
The purpose of this study is to examine young consumers' motives for using SMS, their SMS usage frequency, and their attitudes towards SMS advertising. Factor analysis on the motives for using SMS revealed seven factors, namely convenience, social involvement, enjoyment, escape, personal communication, economical reasons, and public expression. The findings show that convenience and economical reasons influence SMS usage frequency. Social involvement influences attitudes towards SMS advertising. Managerial implications and limitations are also presented.
\end{abstract}

\section{Introduction}

The use of SMS as an advertising medium has received widespread attention in recent years (Carroll et al., 2007; Grant and O'Donohoe, 2007 Leung, 2007; Muk, 2007). Prior studies have been conducted to examine consumer attitudes towards SMS advertising, however it is still limited (Vrechopoulous et al., 2003). Research in this area has investigated a number of aspects of SMS advertising, such as acceptance (Carroll et al., 2007; Rettie and Brum, 2001), uses and gratifications (Leung, 2007; Leung and Wei, 2000), interpersonal influences (Muk, 2007), demographic effects (Okazaki, 2007; Barnes, 2002). However, little has been done to investigate the relationship between motives for using SMS technology and the relationship with attitudes towards SMS as an advertising or promotional tool. Furthermore, past studies have focused on the American, European and Chinese context (such as Muk, 2007; Leung, 2007; Yan et al., 2006), but the Australian perspective is yet to be understood. Although, this medium is suggested to be a potentially effective and profitable channel to advertise targeted messages (Leung, 2007), the Australian youth market's reception towards this medium is still under researched (Grant and O’Donohoe, 2007).

\section{Relevant Literature and Hypotheses Development}

For marketers, SMS advertising provides several advantages, such as cost effectiveness, ubiquity, immediacy, and targeted message delivery (Rettie and Brum, 2001). However, it is found that $79 \%$ of online consumers find receiving mobile ads through their mobile phones irritating and intrusive (Muk, 2007; Grant and O'Donohoe, 2007; Xu, 2006/2007).

Conversely, studies have also found that mobile advertising campaigns generate a higher response rate as compared to direct mail and internet banner ads, thus its potential cannot be undermined (Jelassi and Enders, 2004). Barnes (2002) also found that SMS advertising is more capable of attracting the younger consumer market, whereas other media have found it a challenge to do so.

Motivations for using wireless or SMS technology is derived from the uses and gratification theory. This theory purports that the consumer is actively involved in the decision to determine their media use and is motivated by the need to fulfill certain needs (Peters et al., 2007; O'Donohoe, 1994). Furthermore, these consumers select the media contents that they wish to be exposed to (Katz, 1959). Based on the studies conducted by Katz et al. (1973), the 
use of mass media is goal oriented, and the consumer seeks to link the need gratification with their choice of media. The consumer's use of the media also competes with other sources of need satisfaction and gratifications from media use, which usually encompass diversion, entertainment, escapism, and information (McQuail et al., 1972). The consumer also seeks to satisfy the need to express personal identity and to build relationships through the use of media (McQuail et al., 1972; Katz et al., 1973; Weiss, 1971). Furthermore, social influences and psychological states of consumers also impacts on the decision. Media use is considered as a natural composition of the environment, its use is therefore a part of the consumer's social action and routine. As such, consumers would interpret SMS messages by incorporating it as part of their daily routine (O'Donohoe, 1994). The utilitarian dimension of uses and gratification theory can be applied to examine the consumers' motives for using SMS text messaging (Leung, 2007).

Based on prior studies, there are evidence that consumers utilize SMS on the basis of its convenience, usefulness and ease of use (Grant and O'Donohoe, 2007; Peters et al., 2007; Bagozzi et al., 1992). Furthermore, SMS is infused with the 'fun' factor (Grant and O'Donohoe, 2007), which makes it especially attractive to young consumers. However, the nature of SMS technology is dissimilar to other media, as it is ubiquitous, text based, and personal in nature. Leung's (2007) study revealed six factors, namely entertainment, affection, fashion, escape, convenient and low cost, and coordination. With SMS use gaining a bigger share of our daily media use, this study aims to extend on prior studies to examine the motives for using SMS. As such, the motives for using SMS messaging would also influence the number of SMS a consumer send (Maneesoonthorn and Fortin, 2006). Based on the above discussion, the following research questions are formulated:

RQ1: What are the motives for using SMS?

RQ2: How does motives for using SMS influence SMS usage frequency?

\section{Attitudes towards SMS advertising}

Attitudes are conventionally regarded as an indicator of the effectiveness of advertising (Jun and Lee, 2007). According to Allen et al. (1992), attitudes is defined as the affect or the general sentiment of dislike or like of a particular action or behaviour. According to Fishbein and Ajzen (1975), an attitude towards an object is defined as an individual's internal evaluation based on his or her beliefs. Consumer attitudes towards SMS advertising can be determined by the values that they attribute to SMS advertising (Ducoffe, 1995). Jun and Lee (2007), suggested that when consumers are provided with benefits such as entertainment and information, they will perceive advertising in a more favourable light. In addition, SMS advertising has been suggested to be attention grabbing, an information provider, interesting, and interactive (Maneesoonthorn and Fortin, 2004; Lee et al., 2006).

SMS advertising has been stated to be a more effective medium to generate consumer response (Barnes, 2002). However, it has been found that young consumers hold increasingly negative attitudes towards advertising (Zanot, 1984; Tsang et al., 2004), therefore, it is crucial to examine if negative attitudes towards SMS advertising/promotions would discourage the frequency of using SMS (Jun and Lee, 2007). Hence, the following hypotheses are formulated:

$\mathbf{H}_{1}$ : There is a positive relationship between motives for using SMS and attitudes towards SMS advertising/promotions.

$\mathbf{H}_{2}$ : There is a positive relationship between SMS usage and attitudes towards SMS advertising/promotions. 


\section{Methodology}

Data was collected using a convenience sampling method in a large university in Western Australia. A self administered questionnaire was distributed in a lecture setting that captures the young adult demographic segment. The survey instrument comprised of four sections. Section A consists of a screening question to determine if the respondent has used SMS before, followed by a question on the respondent's weekly SMS usage. Section B consists of an adapted scale from various sources that examines consumer attitudes towards SMS advertising/promotions (Carroll et al., 2007; Lee, Tsai and Jih, 2006). Section C comprised of scale items adapted from Leung (2007) that investigates the motives for using SMS. Both Section B and C are measured on a seven point Likert scale with $1=$ "strongly disagree" and 7 = "strongly agree". Section D consists of questions that capture the respondent's demographic information.

A total of 211 useable responses were collected and used for the analysis. Respondents were mainly males (53.6\%) and the majority of the students (89.6\%) fall between the age group of $18-24.73 .5 \%$ of the respondents are rated as high SMS users (who send more than 9 messages per week), and $26.5 \%$ are low SMS users (who send less than 9 messages per week).

\section{Results}

An exploratory factor analysis was conducted using Varimax rotation on the 30-item uses and gratification scale which constitute the motives for using SMS. Seven factors emerged from the analysis namely, "convenience", "social involvement", "enjoyment", "escape", "personal communication", "economical reasons", and "public expression". These seven factors (motives) explain $63.38 \%$ of the total variance and recorded a KMO of 0.849 . All factors recorded a Cronbach's Alpha of 0.6 and above, which is deemed reliable (Nunnally, 1978).

The seven motives for using SMS were next regressed towards SMS usage per week. The results showed that "convenience" has a significant positive relationship towards SMS usage per week ( $\mathrm{Sig}=.001, \beta=.282$ ) explaining $13.9 \%$ of the variance (See Table 1). This suggests that the higher the perceived convenience for the consumer, the greater the number of SMS sent within a week.

In addition, the seven motives for using SMS were regressed towards high and low SMS users. The two user groups were formed through a median split of usage frequency. It was found that "convenience" has a significant positive influence on user levels (Sig. $=.000$, $\beta=.302$ ). However, "economical reasons" was found to have a significant negative influence towards user levels (Sig. $=.044, \beta=-.143$ ). Both factors account for $11.8 \%$ of the variance.

Next, the seven motives for using SMS were regressed against attitudes towards SMS advertising/promotions. "Social involvement" was found to have a significant and positive influence on attitudes towards SMS advertising/promotions (Sig. $=.000, \beta=.323$, Adj $\mathrm{R}^{2}=$ .091). However, the other factors do not have a significant relationship with attitudes towards SMS advertising/promotions (See Table 1 ). Hence $\mathrm{H}_{1}$ is partially supported. 
Table 1: Regression Analysis

\begin{tabular}{lcc}
\hline Motives for using SMS & $\begin{array}{c}\text { SMS usage frequency } \\
\text { (SMS per week) }\end{array}$ & $\begin{array}{c}\text { Attitudes towards SMS } \\
\text { Advertising/promotions }\end{array}$ \\
\hline Convenience & $.282^{* *}$ & -.011 \\
\hline Social involvement & -.126 & $.323^{* *}$ \\
\hline Enjoyment & .179 & .098 \\
\hline Escape & .136 & -.036 \\
\hline Personal communication & -.075 & .011 \\
\hline Economical reasons & -.080 & .020 \\
\hline Public expression & -.082 & -.015 \\
\hline & $\mathbf{0 . 1 4}$ & $\mathbf{0 . 0 9}$ \\
\hline
\end{tabular}

SMS usage frequency was regressed against attitudes towards SMS advertising/promotions. The results showed that there is no relationship between the frequency of SMS usage and consumers' attitudes towards SMS advertising/promotions (Sig. $=.909, \beta=-.008$, Adj $\mathrm{R}^{2}=$ $.005)$. Hence, $\mathrm{H}_{2}$ is rejected.

\section{Discussion and Managerial Implications}

The study has identified seven factors that influence SMS usage frequency, which are convenience, social involvement, enjoyment, escape, personal communication, economical reasons, and public expression. However, only convenience is found to influence SMS usage frequency of the Australian young consumers, because consumers find that it is quick and easy to use. In addition, convenience is also composed of keeping in touch with friends, and keeping up with everyone. As such, well crafted and relevant advertising messages could well be forwarded and circulated within the social network (Grant and O'Donohoe, 2007).

Marketing strategies such as referrals and promotional vouchers and coupons that are relevant to their interest can be used to reach this market.

Economical reasons is found to negatively influence SMS usage frequency for high SMS users. This can be explained by the fact that heavy users are not concerned about the economical benefits, such as cost control or that phone calls are more expensive. As heavy users, they would understand that the cost of their SMS habit would be relatively substantial. Furthermore, the cost to send an SMS (AUD 0.15 above) in Australia is more expensive than many other countries in Asia and Europe. Most mobile plan rates make it cheaper to call rather than to SMS (i.e. free calls to users of the same service provider). Hence, this could be a reason as to why SMS advertising and SMS technology adoption is much slower in Australia than other nations.

Social involvement is found to be the only factor that influences consumer's attitudes towards SMS advertising. Previous studies have found that a large portion of responses to SMS advertising campaigns is complemented with another media, such as contests that are also 
advertised on TV. In Australia, most of the SMS advertising campaigns are commonly used for voting for a favourite personality on a reality show (for example, Big Brother or So You Think You Can Dance), or to respond to promotions broadcasted on radio. This finding suggests that motivations to participate in contests, voting on reality shows, and to donate to charities are accepted and consumers have a positive acceptance towards such advertising and promotions.

It is found that SMS usage frequency does not influence attitudes towards SMS advertising. This could be due to the fact that consumers utilize SMS for the sake of communication, and do not perceive it to be an advertising channel. It can be argued that because the SMS advertising market in Australia is relatively new, marketers would need to further explore what young consumers would like to benefit from this form of advertising.

There are a number of limitations worthy of improvement and future studies. This study has only examined young consumers in Western Australia, which limits the generalizability across Australia or to other cultures and demographic segments. Furthermore, a cross-cultural study of Australian consumers can also be explored, since Australia is a diverse and multicultural community. Social and personality influences can also be introduced to examine if they influence the motives for using SMS, as well as attitudes towards SMS advertising. In addition, future studies can delve into what forms of SMS advertising messages are relevant and attractive to young consumers in order to influence their attitudes. The emerging popularity of MMS (Multimedia Messaging Service) can also be explored as another avenue to communicate with consumers.

\section{References}

Allen, C., Machleit, K. and Kleine, S., 1991. A comparison of attitudes and emotions as predictors of behavior at diverse levels of behavioral experience. Journal of Consumer Research 18, $493-504$.

Bagozzi, R.P., Davis, F.D. and Warshaw, P.R., 1992. Development and test of a theory of technological learning and usage. Human Relations 45(7), 660 - 686. Barnes, S., 2002. Wireless digital advertising: Nature and implications. International Journal of Advertising 21(3), $399-420$.

Bughin, J.R., 2004. Using mobile phones to boost TV ratings. The McKinsey Quarterly. Available: http://www.mckinseyquarterly.com

Carroll, A., Barnes, S.J., Scornavacca, E., Fletcher, K., 2007. Consumer perceptions and attitudes towards SMS advertising: Recent evidence from New Zealand. International Journal of Advertising 26(1), $79-98$.

Ducoffe, R., 1995. How consumers assess the value of advertising. Journal of Current Issues and Research in Advertising 17(1), $1-18$.

Fishbein, M. and Ajzen, I., 1975. Beliefs, Attitudes, Intention and Behavior: An Introduction to Theory and Research. Reading, MA, Addision-Wesley. 
Grant, I. and O'Donohoe, S., 2007. Why young consumers are not open to mobile marketing communication. International Journal of Advertising 26(2), 223 - 246.

Jun, J.W. and Lee, S., 2007. Mobile media use and its impact on consumer attitudes toward mobile advertising. International Journal of Mobile Marketing 2(1), $50-58$.

Katz, E., Gurevitch, M. and Haas, H., 1973. On the use of mass media for important things. American Sociological Review 38.

Katz, E., 1959. Mass communication research and the study of popular culture: An editorial note on a possible future for this journal. Studies in Public Communication 2, 1 - 6 .

Jelassi, T. and Enders, A., 2004. Leveraging wireless technology for mobile advertising. Proceedings of the $12^{\text {th }}$ European Conference on Information Systems, Turku, Finland, 14 16 June.

Lee, S.F., Tsai, Y.C. and Jih, W.J., 2006. An empirical examination of customer perceptions of mobile advertising. Information Resources Management Journal 19(4).

Leung, L., 2007. Unwillingness-to-communicate and college students' motives in SMS mobile messaging. Telematics and Informatics 24, $115-129$.

Leung, L. and Wei, R., 2000. More than just talk on the move: uses and gratifications of cellular phone. Journalism and Mass Communication Quarterly 77(2), 308 - 320.

Maneesoonthorn, C. and Fortin, D., 2006. Texting behaviour and attitudes toward permission mobile advertising: An empirical study of mobile users' acceptance of SMS for marketing purposes. International Journal of Mobile Marketing 1(1), 66 - 72.

McQuail, D., Blumler, J.G. and Brown, J.R., 1972. The television audience: A revised perspective. In McQuail, D. (ed). Sociology of Mass Communications, Harmondsworth, Penguin.

Muk, A., 2007. Consumers' intentions to opt in to SMS advertising. International Journal of Advertising 26(2), $177-198$.

Nunnally, J. C. 1978. Psychometric theory (2nd ed.). New York: McGraw-Hill

O’Donohoe, S., 1994. Advertising uses and gratifications. European Journal of Marketing $28(8 / 9), 52-75$.

Okazaki, S., 2007. Exploring gender effects in a mobile advertising context: On the evaluation of trust, attitudes, and recall. Sex Roles 57, $897-908$.

Peters, C., Amato, C.H. and Hollenbeck, C.R., 2007. An exploratory investigation of consumers' perceptions of wireless advertising. Journal of Advertising 36(4), $129-145$.

Rettie, R. and Brum, M., 2001. M-Commerce: The role of SMS text messages. In Dholakia, R.R., Kolbe, L., Venkatesh, A. and Zoche, P. eds. COTIM-2001 Conference Proceedings. 
Tsang, M.M., Ho, S.C. and Liang, T.P., 2004. Consumer attitudes toward mobile advertising: An empirical study. International Journal of Electronic Commerce 8(3), 65 - 78.

Vrechopoulous, A., Constantiou, I., Sideris, I., Doukidis, G., and Mylonopoulos, N., 2003.

The critical role of consumer behaviour research in mobile commerce. International Journal of Mobile Communications 1(3), $239-240$.

Weiss, W., 1971. Mass Communication. Annual Review of Psychology 22, 309 - 336.

$\mathrm{Xu}, \mathrm{D} . J ., 2006 / 2007$. The influence of personalization in affecting consumer attitudes toward mobile advertising in China. The Journal of Computer Information Systems 47(2), 9 - 19.

Yan, X., Gong, M. and Thong, J.Y.L., 2006. Two tales of one service: User acceptance of short message service (SMS) in Hong Kong and China. Young Consumer 8(1), 16 - 28.

Zanot, E., 1984. Public attitudes toward advertising: The American experience. International Journal of Advertising 13, $3-15$. 